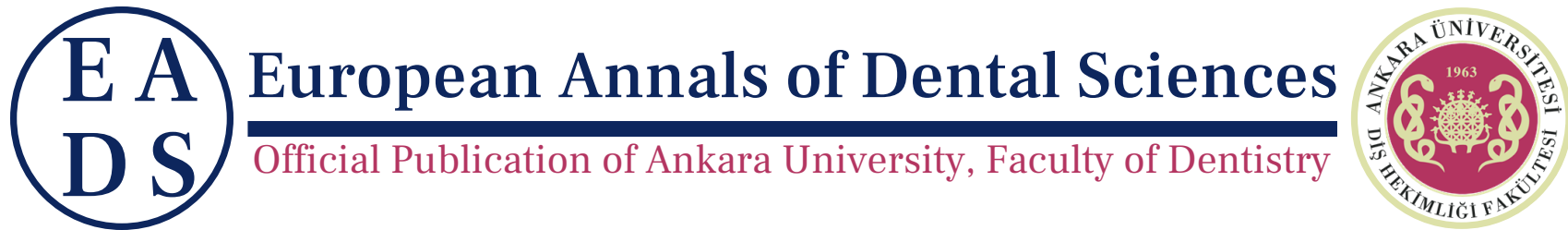

EADS, 2021, 48 (Suppl), S8-10

\title{
An Overview of Maxillofacial Radiology Education Activities During and after the Covid-19 Pandemic
}

\author{
Elif Polat $\odot *$ and Candan S. Paksoy \\ Department of Dentomaxillofacial Radiology, Faculty of Dentistry, Ankara University, Ankara, TURKEY \\ *Corresponding Author; dtelifpolat@hotmail.com
}

\begin{abstract}
During the COVID-19 pandemic, the disruptions in educational activities at all levels and fields all over the world were reflected in maxillofacial radiology education. During the COVID-19 pandemic period, theoretical education has been tried to be continued in the form of online education, although various studies showed that online education is insufficient in practical education. After the pandemic, it is predicted that returning to normal maxillofacial radiology education will be challenging in both theoretical and practical aspects and there will be a need to change. Considering the strengths and weaknesses of online education models, whose application area has increased so much during the COVID-19 pandemic. The development and implementation of new, effective education-training models suitable both for the conditions and for everyone involved in education for the post-pandemic period, emerges as a necessity. After the pandemic, it is important to evaluate the blended education model in theoretical education, to make various changes in maxillofacial radiology practical training, and to re-determine the rules of hygiene, separation, and education. The article aims is to convey the applications of online education in the field of maxillofacial radiology, which is widely used in the world during the COVID- 19 pandemic, and the post-pandemic education and training models suggestions by the changing world order by compiling the research results and literature information on the subject.
\end{abstract}

Key words: COVID 19; maxillofacial radiology; online education

\section{Introduction}

Diagnosis and treatment planning are some of the basic competence areas of dentistry. Radiological examination methods are used as complementary to the anamnesis and clinical examination in diagnosis and treatment planning. Rapid technological developments in recent years have permanently changed economic, social and professional life. Information and communication technologies have developed very rapidly, and their recognition has increased all over the world. This situation has changed educational methods and enabled education to be more dynamic and appeal to large masses. In particular, integrating technology into university education is no longer an option but a necessity. It was stated that failing to do so would be considered professional irresponsibility. ${ }^{1}$

Based on this point, it has become inevitable to integrate information technologies, including the internet and electronic learning, into the educational program as a source of information to increase the learning experience of students. As a result of these developments, online education has emerged. We can define online education as a modern education system where students and teachers are not obliged to come to the campus, in a completely virtual environment, live, visual, audio, independent of time and place, interactively. ${ }^{2}$ The effectiveness and usefulness of online education in many subjects are known. Students who cannot find face-to-face education (disabled individuals, sick individuals for a certain period, migration, transportation ...) can reach many educational opportunities. Cause it is a more centralized system, it increases the quality of education. It provides faster transfer of technological developments. All people can benefit from education equally. It can also reduce education expenses. It provides the opportunity to establish effective communication between students and educators living in different countries of the world. It provides comfort to students with psychological problems (egg social phobia). It provides freedom of navigation and the ability to repeat the application. ${ }^{2}$ These positive examples can be increased. From a pedagogical perspective, electronic education has the potential to transform the paradigm from passive teacher-centered learning to active student-centered learning. ${ }^{1}$ It also opened the way for online education combined education. We can define combined education as a hybrid education model that online education and classroom education (traditional education) are applied together.

Dentistry schools have also started to support face-to-face education with distance education tools. Examples of these online edu- 
cation tools are webcasting (computer-based activities), portable digital devices, online evaluation, electronic databases, virtual libraries, video-assisted clinical teaching, online discussion and common studies, clinical simulators, and virtual reality technologies. ${ }^{1}$

Organized studies on pre-graduate education and training methods in the field of oral diagnosis and dentistry radiology have been carried out since 1985. Distance education model in maxillofacial radiology; It includes PowerPoint presentations, educational films, textbooks, congress summary books and articles, presentation of clinical cases through various social media accounts, virtual test applications, communication with the mentor via e-mail. ${ }^{3}$

Skype, Zoom, Instagram ${ }^{\circledR}$, Facebook ${ }^{\circledR}$, YouTube, Twitter ${ }^{\circledR}$, LinkedIn ${ }^{\circledR}$, Pinterest ${ }^{\circledR}$ are social media tools that can be used in the maxillofacial radiology distance education model. ${ }^{4}$ In addition to all these easiest and benefits, there are some inadequacies and disadvantages of online education. The most important of these are the difficulties in handling their practical applications in laboratories and workshops. Another difficulty is the absence of group discussions and communication with peers. Setting up online education network can be costly in some countries. Not every student and teacher have the ability to access and use computers is also considered a limitation of online education. ${ }^{3}$

According to the WHO's January 2021 report, 1,889,449 people died in the COVID-19 pandemic, 87,273,380 people were infected, and billions of people were physically, mentally, and economically affected by this pandemic. Healthcare and education services are the most affected areas by the pandemic. Especially during the pandemic, applied online education models applied in these conditions have been a hope for clinical education and service in maxillofacial radiology.

A study which was conducted by Howerton et al. ${ }^{5}$, it was examined the success of computer-aided education in students' wholemouth periapical film shooting. While a group of students received traditional training on long cone technique and film shooting, the other group was given 27 different videos and CDs that showing to periapical film shooting and containing lectures. After the training, the students were asked to take full-mouth periapical films from the models. As a result, students who received computer-aided education made more mistakes in whole-mouth periapical film shooting than students who had traditional education. Despite this, the survey results showed that they liked the online training method. This is the first study that examines the effect of computer-aided education in clinical practice and shows the deficiency of online education in terms of clinical practice. ${ }^{5}$

In a study conducted by Hassan et al. ${ }^{6}$, it was concluded that the web-based training module developed for bone anatomy training in CBCT images will assist in understanding and interpreting craniofacial anatomy in the images.Wenzel et al. ${ }^{7}$ compared the effectiveness of a traditional radiology book with an interactive digital tool in learning radiological anatomy. The research showed that in the computer-aided method learning abilities increased and that the student was more interested in and used the course material. It has been found that the use of the digital tool is easier, safer, and more useful than a book. Many students stated that using books and digital tools together would be more effective.Another study which was carried out by Kavadella et al. ${ }^{1}$ at the University of Athens, it was compared the theoretical success of the online education model and the traditional education model, and it was concluded that the distance education model was significantly more successful.

Soltanimehr et al. ${ }^{3}$ compared the traditional education and combined education models and stated that although combined education has a theoretical superiority, it was lacking in practical terms. To prevent the spread of infection during COVID-19, isolation and social distancing measures have been determined by many countries. With the suspension of classroom lectures by most universities, the need to implement and improve online education has become very important and essential. ${ }^{4}$ Applications such as Zoom, Microsoft Teams, and GoToWebinar were used to continue edu- cation in maxillofacial radiology worldwide. Free viewable webinars by various organizations including the European Society of Radiology, Royal Society of Medicine, Radiopaedia have become popular. Social media platforms such as Instagram and Twitter also provided the opportunity for educators to share content. Various radiology associations took action to provide a comprehensive webinar for trainers and students at the national level. For Dental Schools it is imperative to adopt a strict protocol that accelerates the service, increases biosecurity, and also maintains the educational process. To slow the spread of COVID-19, it is important to balance social distancing and at the same time maintain the workforce required to provide clinical patient care. Theoretical activities for post-pandemic can be carried out remotely. Studies have shown that a correctly applied online education is as sufficient as traditional learning in maxillofacial radiology. ${ }^{1,3,8}$ It has been observed that online education eliminates the unnecessary crowd of people and the associated infection risk. In practical terms, limiting the radiographic technique and interpretation classes to only one person, setting updated infection control procedures, extraoral imaging such as panoramic radiography, and cone-beam computed tomography may be valid alternatives during the COVID-19 outbreak.8 Still, Periapical radiographs are indispensable in many clinical situations. ${ }^{8}$ After the COVID-19 pandemic, periapical radiography should be performed under the guidance of renewed infection control procedures. ${ }^{8}$

Some Specific Recommendations and Reorganizations for Maxillofacial Radiology Departments in Dental Schools

- Undergraduate students should be divided into small groups and the number of patients entering the clinic at one time should be reduced. ${ }^{9}$

- In the first years of applied training in maxillofacial radiology, intraoral radiography training should be done with anthropomorphic phantoms. ${ }^{9}$

- Training on the indications and application of extraoral imaging techniques should be preferred in intermediate and advanced classes. ${ }^{9}$

- Students, trainers, and staff must wear disposable surgical gowns and mask.

- Imaging receptors should be a double barrier to prevent perforation and cross-contamination. ${ }^{8}$

- During the pandemic period, patients should be taken to the examination and radiography room after proper triage only for emergencies.

- During registration, contamination can pass between staff and patients through paper and pen, so it is important to use a digital system among staff as well. ${ }^{8}$

- Printed radiographs may deteriorate during disinfection and cause contamination. Therefore, institutional digital platforms should be developed to provide imaging transfer, remote diagnosis, outcome control, and clinical case discussion by students. ${ }^{8}$

- The distance between the $x$-ray room and the examination room must follow a standard guide to prevent aerosol passage. ${ }^{10}$

- In the $x$-ray room, negative pressure facilities are recommended to keep the potential viral load to a minimum. ${ }^{10}$

- Extraoral radiographs such as dental panoramic or conical beam computed tomography should be preferred instead of intraoral radiographs. $^{8}$

- In cases where periapical radiographs are unavoidable, the patient should be given mouthwash containing oxidative agents such as $0.2 \%$ povidone or $1 \%$ hydrogen peroxide. ${ }^{10}$

- Precautions should be taken to prevent reflexes such as gagging and coughing that will accelerate the spread of coronavirus. ${ }^{10}$ 


\section{Conclusion}

Social media provides lecturer feedback and promotes active learning, considered best practices for the teaching-learning process. Systematic reviews have shown that online education in maxillofacial radiology is theoretically as effective as traditional education methods. The students stated that computers, the internet, and social media provided the opportunity to reinforce the lessons and showed parallel results in the theoretical exams. Such results, indicating better student performance in online developed courses, have recently been featured in the educational literature. Nevertheless, how to give radiology practical training to students and how to ensure student's attention and active participation is one of the biggest problems. Not all students have equal conditions for internet access. Some of the students return to countries with limited or weak internet access, limited computer access, difficulties in adapting to the distance education model of teachers and students, lack of prior education for effective web-based learning practices as the difficulties of distance education during the pandemic. In addition, because images are usually sent and stored over the internet, care should be taken to store confidential data regarding the sharing of patient information.

All experience indicates that distance education will be more than a necessity in the coming period. Especially, ensuring the continuity of service and education is very important in maxillofacial radiology, which is an indispensable branch for the scientific continuity of dentistry. Data obtained as a result of studies showed that distance education still has shortcomings in radiology practical training. Despite some drawbacks, the integration of online learning into radiology education should be utilized rapidly. It is inevitable to change hygiene habits after the pandemic and to make necessary changes in maxillofacial radiology education.

None

\section{Author Contributions}

E.P.: Designed the study, Reviewed the literature, Wrote the manuscript. CSP: Designed the study, Reviewed the literature, Approved the final manuscript

\section{Conflict of Interest}

Authors declare that they have no conflict of interest.

\section{Authors' ORCID(s)}

E.P. $\quad 0000-0001-9952-0548$

C.S.P. $0000-0002-6961-5172$

\section{References}

1. Kavadella A, Tsiklakis K, Vougiouklakis G, Lionarakis A. Evaluation of a blended learning course for teaching oral radiology to undergraduate dental students. Eur J Dent Educ. 2012;16(1):e88-95. doi:10.1111/j.1600-0579.2011.00680.x.

2. Calli I, Isman A, Torkul O. Sakarya Üniversitesi'nde uzaktan eğitimin dünü bugünü ve geleceği. SUJEF. 2002;0(3).

3. Soltanimehr E, Bahrampour E, Imani MM, Rahimi F, Almasi B, Moattari M. Effect of virtual versus traditional education on theoretical knowledge and reporting skills of dental students in radiographic interpretation of bony lesions of the jaw. BMC Med Educ. 2019;19(1):233. doi:10.1186/s12909-019-1649-0.

4. Pontual MLA, do Nascimento EHL, da Cruz Perez DE, Pontual AA, Ramos-Perez FM. Challenges in oral radiology teaching during COVID-19 pandemic. Dentomaxillofac Radiol. 2020;49(5):20200178. doi:10.1259/dmfr.20200178.

5. Howerton J W B, Platin E, Ludlow J, Tyndall DA. The influence of computer-assisted instruction on acquiring early skills in intraoral radiography. J Dent Educ. 2002;66(10):1154-8.

6. Hassan BA, Jacobs R, Scarfe WC, Al-Rawi WT. A web-based instruction module for interpretation of craniofacial cone beam CT anatomy. Dentomaxillofac Radiol. 2007;36(6):348-55. doi:10.1259/dmfr/61627346.

7. Wenzel A, Gotfredsen E. Computer-assisted instruction for intraoral radiography. Part II. Evaluation of program effectiveness. Dentomaxillofac Radiol. 1985;14(2):129-32. doi:10.1259/dmfr.1985.0018

8. Rosa B, Ferreira MD, Moreira GC, Bastos MF, Pinto RR, Visconti $\mathrm{MA}$, et al. The COVID-19 post-pandemic scenario to Oral Radiology at Dental Schools. Oral Radiol. 2020;36(4):406-407. doi:10.1007/s11282-020-00466-7.

9. Fontenele RC, Gomes AF, Freitas DQ. Oral radiology practice in dental schools during the COVID-19 pandemic: What will be the new normal? Imaging Sci Dent. 2020;50(3):265-267. doi:10.5624/isd.2020.50.3.265.

10. Saki M, Haseli S, Iranpour P. Oral Radiology Center as a Potential Source of COVID-19 Transmission; Points to Consider. Acad Radiol. 2020;27(7):1047-1048. doi:10.1016/j.acra.2020.04.040. 